\title{
EFEITO DA CONCENTRAÇÃO DE POTÁSSIO NA EFICIÊNCIA DO EXTRATO DE SEMENTES DE MORINGA COMO AGENTE COAGULANTE
}

\author{
Mateus Pimentel de Matos ${ }^{1}$, Ivan Célio Andrade Ribeiro ${ }^{2}$, Ana Paula Silva Batista ${ }^{3}$, Edson Faria da Silva ${ }^{4}$
}

\section{RESUMO}

Estudos indicam que sais potencializam o efeito coagulante do extrato de sementes de moringa (Moringa oleifera), tendo sido obtidos resultados satisfatórios quando preparado em solução de cloreto de sódio e hidróxido de cálcio. Entretanto, a presença de íons monovalentes em águas residuárias pode favorecer a dispersão dos sólidos, impedindo a formação de flocos e a sedimentação dos sólidos, reduzindo a eficiência de redução na turbidez. Sabe-se que o efluente de filtros orgânicos, gerado, por exemplo, quando se utiliza serragem de madeira como material filtrante, e águas residuárias como as do processamento do fruto do cafeeiro e vinhaça, apresentam altas concentrações do íon monovalente potássio. No presente trabalho, objetivou-se avaliar a eficiência do extrato de sementes de moringa, como agente coagulante, na remoção de turbidez de água (turbidez de 106 UNT) com concentrações de potássio de 0 a $375 \mathrm{mg} \mathrm{L}^{-1}$. Verificou-se que o potássio, quando presente em concentrações de até $2 \mathrm{mg} \mathrm{L}^{-1}$, proporcionou efeito dispersivo no material sólido em suspensão, entretanto, a partir daí, crescente eficiência na coagulação dos sólidos presentes e, consequentemente, redução na turbidez da água.

Palavras-chave: coagulação, dispersão, turbidez.

\section{ABSTRACT \\ EFFECT OF POTASSIUM CONCENTRATION ON EFFICIENCY OF SEED EXTRACT MORINGA AS A COAGULATING AGENT}

Studies indicate that salt solutions potentiate the coagulant power of the moringa (Moringa oleifera) seed extract and satisfactory results have been obtained when prepared in solutions of sodium chloride and calcium hydroxide. However, the presence of monovalent ions in wastewater may favor the dispersion of solids, preventing the formation of flocs and sedimentation of solids, reducing the efficiency of reduction in turbidity. It is known that the effluent from organic filters, for example generated when using sawdust as filtering material, and wastewaters such as that from the processing of the coffee fruit and vinasse, have high monovalent potassium ion concentrations. The present study aimed to evaluate the efficiency of moringa seed extract as coagulant, in the removal of turbidity from water (turbidity $106 \mathrm{NTU}$ ) with potassium concentrations from 0 to $320 \mathrm{mg} \mathrm{L}^{-1}$. It was found that potassium, when present in concentrations of up to $2 \mathrm{mg} \mathrm{L}^{-1}$, resulted in dispersive effects, but in higher concentrations greater coagulation efficiency of solids present, and consequently reduced water turbidity.

Keywords: coagulant, dispersion, turbidity.

Recebido para publicação em 28/05/2012. Aprovado em 20/06/2013.

1- Engenheiro Agrícola e Ambiental, Doutorando em Engenharia Sanitária e Ambiental, mateus.matos@ufv.br.

2 - Estudante de Engenharia Agrícola e Ambiental, ivan.ribeiro@ufv.br.

3 - Estudante de Engenharia Agrícola e Ambiental, anapsbatista@gmail.com.

4 - Engenheiro Agrícola e Ambiental, Doutorando em Engenharia Agrícola e Ambiental, edsfaria@yahoo.com.br.

476 REVENG

476-481p. ENGENHARIA NA AGRICULTURA, VIÇOSA - MG, V.21 N.5, SETEMBRO / OUTUBRO 2013 


\section{INTRODUÇÃO}

A Moringa oleifera, espécie vegetal que tem sido muito estudada atualmente, em virtude de seu efeito coagulante no tratamento da água e esgotos, é uma planta tropical, pertencente à família de Moringaceae, nativa da Índia. No Brasil é conhecida também como quiabo de quina e lírio branco (NDABIGENGESERE, 1995; MATOS, 2002).

De crescimento rápido, essa árvore pode alcançar 4,0 $\mathrm{m}$ de altura no primeiro ano, havendo relatos de plantas com até 12 metros de altura. Além de ser de acelerado desenvolvimento, essa espécie tem boa adaptabilidade a diversas condições naturais. Suporta longos períodos de estiagem, em parte por ser caducifólia; solos pobres; e cresce bem em condições semiáridas e em ampla faixa de $\mathrm{pH}$ (5 a 9). Quando adulta, pode alcançar produção anual de 3 a 5 toneladas de sementes por hectare (MORTON, 1991; ESNARRIAGA et al., 2011). Por ser uma planta que não requer cuidados especiais e que cresce e produz bem em diversas condições ambientais, tem sido tema de diversos trabalhos relativos aos possíveis benefícios que possa trazer, em diversas atividades.

Diversas utilidades já foram descobertas para as sementes, folhas, flores e vagens, podendo, por exemplo, seremutilizadosnaindústria farmacêutica, cosmética e alimentícia, como lubrificantes e biocombustíveis (LILLIEHOOK, 2005). Além disso, foi verificado que o óleo da semente da moringa possui propriedades antissépticas e antiinflamatórias, as quais foram descritas por Santos et al. (2011). Descobertas recentes apontam que o extrato aquoso das sementes de moringa é eficaz no combate das larvas de mosquito da Dengue e Febre Amarela. Ferreira et al. (2009), constataram que doses de $5.200 \mu \mathrm{g} \mathrm{mL}^{-1}$ do extrato da semente são suficientes para causar mortandade de 99,2\% das larvas, sem ser tóxico a animais e humanos. Tal efeito xenobiótico se deve à presença de substâncias nocivas aos micro-organismos nos cotilédones das sementes (AL AZHARIA JAHN, 1986), as quais têm grande importância, também, no tratamento de água, para remoção de organismos patogênicos. Pesquisadores, como Nishi et al. (2011), conseguiram remoções maiores que $90 \%$ de protozoários utilizando concentrações de $150 \mathrm{mg}$ $\mathrm{L}^{-1}$ de extrato de semente de moringa. Em adição à remoção de patógenos, o extrato de sementes de moringa também favorece o tratamento de águas de abastecimento e residuárias, por proporcionar redução na sua turbidez, sendo esta a propriedade mais estudada dessa espécie vegetal.

Segundo Ndabigengesere et al. (1995), as principais responsáveis pelo efeito aglutinador de partículas em suspensão são as proteínas de alto peso molecular, presentes nas sementes. Essas funcionam como os polieletrólitos catiônicos que, em contato com as impurezas da água, se ionizam, provocando a desestabilização das partículas, fazendo com que os sólidos em suspensão floculem.

Pesquisas indicam que o efeito aglutinador do extrato de semente de moringa pode ser potencializado com a adição de sais ao coagulante (OKUDA et al., 1999). Os autores verificaram que $1 \mathrm{~mol}_{c} \mathrm{~L}^{-1}$ de $\mathrm{NaCl}$ fez com que o processo de coagulação com extrato de moringa fosse mais eficiente, até mesmo quando a concentração do coagulante era 7,4 vezes menor que a do tratamento em que não foi adicionado o sal. Em outro trabalho, Okuda et al. (2001) observaram que cátions bivalentes são mais efetivos na formação de flocos, em estrutura tipo rede, capazes de promover o arraste, para o fundo do reservatório, de sólidos em suspensão na água. Lo Monaco et al. (2012), por sua vez, analisando águas residuárias da suinocultura (ARS), não verificaram aumento na remoção de sólidos com adição de $1 \mathrm{~mol}_{c} \mathrm{~L}^{-1}$ de $\mathrm{NaCl}$ e, também, que não havia diferença entre o uso de extrato de moringa com adição de cal hidratada e o simples acréscimo desse sal. Segundo os autores, tais resultados podem estar relacionados às próprias características da água residuária da suinocultura usada no experimento. Argumentaram que, na limpeza das baias dos animais, as fezes são raspadas, antes da lavagem do piso do criatório dos animais, o que proporciona a geração de uma água residuária contendo mais urina e material orgânico com menores dimensões, apresentando, essa ARS, mais sólidos dissolvidos, menos afetados pelo tratamento com o coagulante natural.

Por outro lado, sabe-se que a presença de sais de cátions monovalentes pode trazer prejuízos à coagulação de partículas em suspensão na água, 
tendo em vista que são íons dispersantes que, por possuírem grande raio hidratado, o que proporciona aumento na espessura da dupla camada difusa, podem concorrer para aumento na força de repulsão entre as partículas. Por essa razão, o hidróxido de sódio é usado na separação das frações silte e argila, na análise granulométrica do solo (MATOS, 2010; MAURI et al., 2011).

Matos et al. (2013), avaliando o efeito de diferentes concentrações de sementes trituradas de moringa no efluente de filtro orgânico de serragem de madeira, utilizado no tratamento de esgoto sanitário, verificaram efeito prejudicial do aumento da concentração de extrato de sementes de moringa na remoção da turbidez. Os autores atribuíram a solutos, possivelmente potássio e/ou sódio, lixiviado do filtro orgânico de serragem de madeira, a responsabilidade pela diminuição no poder coagulante das sementes trituradas de moringa. As concentrações de $\mathrm{K}$ e Na, notadamente aquelas presentes no efluente dos primeiros volumes de poros filtrados, são altas, especialmente quando se utilizam, por exemplo, serragem de madeira ou bagaço de cana-de-açúcar como material filtrante (BRANDÃO et al., 2003). Como essa forma de tratamento primário é alternativa viável no tratamento de águas residuárias agroindustriais ou rurais, e poderia reduzir o requerimento pelo coagulante natural, necessitase entender melhor em que condições e em que magnitude a presença de potássio em solução pode vir a prejudicar (ou potencializar) o efeito coagulante do extrato de sementes de moringa. Assim, no presente trabalho, objetivou-se avaliar a interferência do potássio, quando presente em diferentes concentrações, na eficiência do extrato de sementes de moringa utilizado para remoção de turbidez de água superficial.

\section{MATERIAIS E MÉTODOS}

Primeiramente, foi feita a análise química do lixiviado do filtro orgânico de serragem de madeira, com o intuito de se obter a concentração de sódio e potássio no efluente, com a aplicação de um volume de poros (volume de espaços vazios na coluna filtrante) de água destilada.

Sendo a porosidade drenável do filtro de serragem de madeira de $0,58 \mathrm{~cm}^{3} \mathrm{~cm}^{-3}$, relação obtida em testes anteriores, foi colocado em uma proveta $0,58 \mathrm{~L}$ de água destilada para cada litro de serragem, tendo sido removida a solução logo após o enchimento da proveta com água. Desta forma, foi simulada a obtenção do efluente relativo à passagem de um volume de poros na coluna filtrante. Na solução obtida, foram quantificadas as concentrações de sódio e potássio, em fotômetro de chama, obtendo, respectivamente, 29,5 e 224,0 mg L ${ }^{-1}$, o que confirmou a maior importância (em termos quantitativos) do último cátion no lixiviado do filtro de serragem de madeira. Esses resultados justificaram o estudo da influência desse cátion monovalente no poder coagulante do extrato de sementes de moringa, cujo método experimental está descrito abaixo.

Amostras da água da represa da Hidráulica, pertencente à Universidade Federal de Viçosa (UFV), foram misturadas com solo da região (Latossolo Vermelho-Amarelo), na proporção de $10,0 \mathrm{~g}$ por litro, para aumentar sua turbidez, a fim de facilitar a observação do efeito dos tratamentos. A turbidez inicial foi medida em turbidímetro.

Para o preparo do extrato de sementes de moringa, 10,0 g de sementes foram trituradas em liquidificador contendo um litro de água destilada. Após preparada a suspensão, dela foram retiradas alíquotas para que fossem obtidas as concentrações de $0,4 \mathrm{~g}$ de sementes por litro de água a ser tratada, em béqueres de $500 \mathrm{~mL}$. Nas misturas água + suspensão de sementes de moringa foi adicionado o nitrato de potássio, para que se obtivessem diferentes concentrações de potássio. No primeiro teste, foram estabelecidas as concentrações de 0 ; $75 ; 150 ; 225 ; 300$ e $375 \mathrm{mg} \mathrm{L}^{-1}$ de potássio. A fim de se verificar o efeito de baixas concentrações de $\mathrm{K}$ na capacidade do extrato de sementes de moringa de remover turbidez, um segundo teste foi conduzido e, para isso, foram utilizadas as concentrações de $0 ; 1 ; 2 ; 5 ; 10 ; 20 ; 30 ; 40 ; 80 ; 160$; 200 e $320 \mathrm{mg} \mathrm{L}^{-1}$ de $\mathrm{K}$.

Após a mistura da água de alta turbidez, com as diversas concentrações de potássio, e com o extrato de semente de moringa, foi feito o teste do Jarro (JarTest), que consiste na agitação por $30 \mathrm{~s} \mathrm{a} 160 \mathrm{rpm}$ e, posteriormente, por $15 \mathrm{~min}$ a $15 \mathrm{rpm}$, deixando em repouso por 10 min (Figura 1). Do sobrenadante, retiraram-se alíquotas para análise da turbidez. 


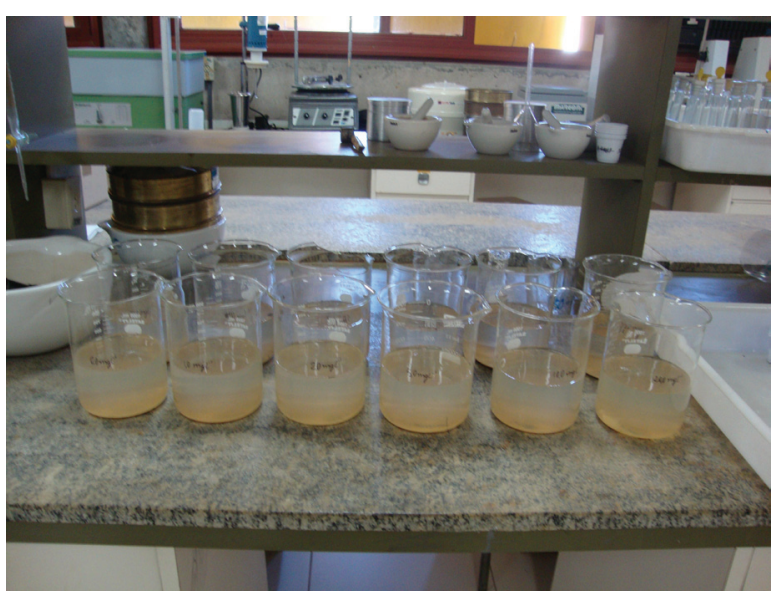

Figura 1. Período de repouso para decantação das amostras, contendo diferentes concentrações de potássio, após efetuado o preparo no Jar-Test.

\section{RESULTADOS E DISCUSSÃO}

A turbidez nas amostras de água turva com 0,4 $\mathrm{g} \mathrm{L}^{-1}$ de sementes trituradas de moringa e diferentes concentrações de potássio estão apresentada na Figura 2. Verifica-se que o aumento na concentração de potássio potencializou, ainda que de forma discreta, o efeito coagulante do extrato de semente de moringa.

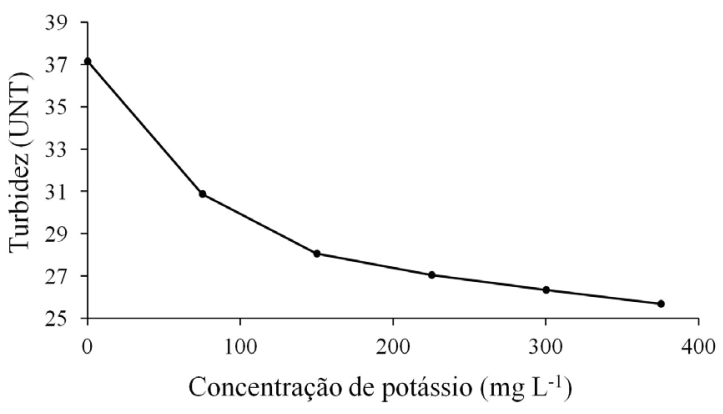

Figura 2. Turbidez na água contendo extrato de sementes de moringa como função da concentração de potássio na água em tratamento (Teste I).

Os resultados de remoção de turbidez da água superficial do segundo teste (Teste II), no qual foram avaliadas concentrações mais baixas de potássio, estão apresentados na Figura 3.

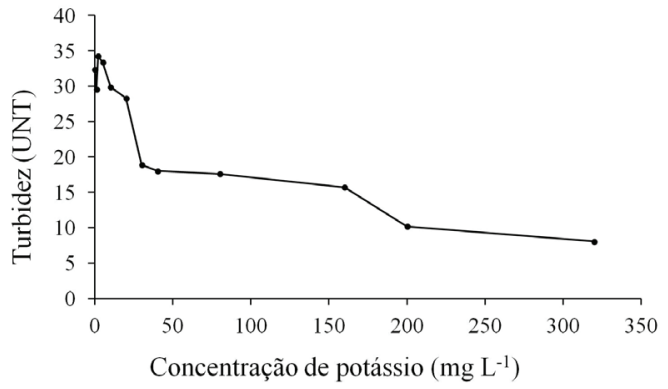

Figura 3. Turbidez como função da concentração de potássio na água em tratamento (Teste II).

Na Figura 3, em razão da medição da turbidez na água contendo baixas concentrações de K, puderam ser observados efeitos diferentes do potássio dependendo da sua concentração. Na faixa de concentração de 0 a $1,0 \mathrm{mg} \mathrm{L}^{-1}$, percebeu-se pequeno declínio na turbidez da água, decorrente, possivelmente, de um efeito potencializador no extrato de sementes de moringa como coagulante, conforme observado por OKUDA et al. (1999). Em sequência, na faixa de 1,0 a 2,0 $\mathrm{mg} \mathrm{L}^{-1}$, ocorreu aumento na turbidez da água, o que pode estar associado ao efeito dispersante do potássio e ao acréscimo de sólidos em suspensão proveniente do próprio extrato de sementes de moringa. Posteriormente, a partir da concentração de 2,0 mg L ${ }^{-1}$, passou a ocorrer, novamente, decréscimo na turbidez da água, o que, aparentemente, está associado ao efeito salino proporcionado pelas altas concentrações de potássio e nitrato no meio. A salinidade do meio proporciona efeito coagulante de sólidos em suspensão, tendo em vista que proporciona redução na espessura da dupla camada difusa e, com isso, possibilidade de coagulação/floculação das partículas em suspensão (BERNARDO; DANTAS, 2005; MATOS, 2010).

Com base nos resultados obtidos, verificou-se que, apenas na faixa de concentração de $\mathrm{K}$ de 1,0 a $2,0 \mathrm{mg} \mathrm{L}^{-1}$ houve ação contrária das forças de dispersão às de coagulação do extrato de sementes de moringa, sendo que, a partir daí, ocorreu aumento crescente na remoção de turbidez. O aumento na concentração de $\mathrm{K}$ proporcionou suficiente redução na espessura da dupla camada difusa dos colóides em suspensão, o que favoreceu a coagulação/floculação dos sólidos em suspensão e a clarificação da água. 
Considerando que a concentração de potássio encontrada no lixiviado de filtro de serragem de madeira foi de $224 \mathrm{mg} \mathrm{L}^{-1}$ e está na faixa considerada favorável à coagulação, verificou-se que não foi a presença desse cátion o que estaria prejudicando a coagulação/floculação das partículas sólidas pelo extrato de sementes de moringa.

\section{CONCLUSÕES}

Com base nos resultados obtidos pode-se concluir que:

- A turbidez da água superficial turva tratada com extrato de sementes de moringa dependeu da concentração de potássio em solução;

- Concentrações de potássio em solução na faixa de 1,0 a 2,0 $\mathrm{mg} \mathrm{L}^{-1}$ proporcionaram aumento, enquanto as maiores $2,0 \mathrm{mg} \mathrm{L}^{-1}$ proporcionaram diminuição na turbidez da água superficial;

- Não foram encontradas evidências de efeito prejudicial do potássio à coagulação proporcionada pelo extrato de semente de moringa.

\section{REFERÊNCIAS BIBLIOGRÁFICAS}

AL AZHARIA JAHN, S. Proper use of African Natural Coagulants for Rural Water Supplies: Research in the Sudan and a Guide for New Projects. Eschborn, GTZ; Germany, 1986. 541p.

BRANDÃO; V.S.; MATOS, A.T; FONTES, M.P.F; MARTINEZ, M.A. Retenção de poluentes em filtros orgânicos operando com águas residuárias da suinocultura. Revista Brasileira de Engenharia Agrícola e Ambiental, Campina Grande, v.7, n.2, p.329-334. 2003.

BERNARDO, L.; DANTAS, A.B. . Métodos e Técnicas de Tratamento de Água. 2. ed. São Carlos: RIMA Editora, 2005. v.02. 1565p.

ESNARRIAGA, E.S.; GALVANI, F.; SOARES, M.T.S.; LISITA, F.O. Influência do uso de sementes trituradas de moringa oleífera no tratamento de efluente bruto de fossa séptica biodigestora ENCONTRO NACIONAL
SOBRE METODOLOGIAS E GESTÃO DE LABORATÓRIOSDAEMBRAPA, 16.;SIMPÓSIO SOBRE METOLOGIA DE LABORATÓRIO DE PESQUISA AGROPECUÁRIA, 3., Bento Gonçalves, 2011. Anais... Bento Gonçalves: Embrapa Uva e Vinho, 2011. p.17.

FERREIRA, P.M.P.; CARVALHO, A.F.U.; FARIAS, D.F.; CARIOLANO, N.G. MELO, V.M.M.; QUEIROZ, M.G.R.; MARTINS, A.L.M. C. NETO, J.G.M. Larvicidal activity of the water extract of Moringa oleifera seeds against Aedes aegypti and its toxicity upon laboratory animals. Anais da Academia Brasileira de Ciências, Rio de Janeiro, v.81, n.2, p.207-216, 2009.

\section{LILLIEHOOK, H. Use of Sand Filtration of River} Water Floculated with moringa oleifera. 2005 27f. Master's Thesis - Department of Civil and Environmental Engineering, Division of Sanitary Engineering. Lulea University of Technology, Lulea, 2005.

LO MONACO, P.A.V.; MATOS, A.T.; EUSTÁQUIO JÚNIOR, V.; NASCIMENTO, F.S.; PAIVA, E.C.R. Ação coagulante do extrato de sementes de moringa preparado em diferentes substâncias químicas. Engenharia na Agricultura, Viçosa, v.20, n.5, set/out, 2012.

MATOS, A.T. Poluição Ambiental: Impactos no Meio Físico. Viçosa, MG: UFV, 2010. 260p.

MATOS, F.J.A. Farmácias Vivas: sistema de utilização de plantas medicinais projetado para pequenas comunidades. 4. ed. Fortaleza: Editora UFC. v.1.267p, 2002.

MATOS, M.P.; BATISTA, A.P.S.; RIBEIRO, I.C.A.; SILVA, E.F. Tratamento de esgoto sanitário em filtro orgânico seguido por coagulação com adição de extrato de sementes de moringa. Revista Engenharia na Agricultura, Viçosa, 2013 (no prelo).

MAURI, J.; RUIZ, H.A.; FERNANDES, R.B.A.; KER, J.C.; REZENDE, L.R.M. Dispersantes químicos na análise granulométrica de latossolos. Revista Brasileira de Ciência do Solo, v.35, p.1277-1284, 2011.

\section{REVENG}


MORTON, J.F. The horsedish tree. Moringa pterygosperma (moringaceae): a boom to arid lands? Economic Botany, Ypsilanti, v.45, n.3, p.318-333, 1991.

NDABIGENGESERE, A.; NARASIAH, K.S.; TALBOLT, B.G. Active agents and mechanism of coagulation of turbid waters using Moringa oleifera. Water Research, Londres, v.29, n.2, p.703-10, 1995.

NISHI, L.; MADRONA, G.S.; VIEIRA, A.M.S; BASSETTI, F.J.; SILVA, G.F.; BERGAMASCO, R. Coagulação/Floculação com sementes de Moringa oleifera Lam para remoção de cistos de Giardia spp. e Oocistos de Cryptosporidiumspp. daágua. International workshop advances in cleaner production: Cleaner production initiatives and challenges for a sustainable world, 3rd. São Paulo. Brasil, 2011. Proceedings... São Paulo, 2011. CD-Rom
OKUDA, T.; BAES, A.U.; NISHIJIMA, W.; OKADA, M. Improvement of extraction method of coagulation active components from moringa oleifera seed. Water Research, Londres, v.33, n.15, p.3373-3378, 1999.

OKUDA, T.; BAES, A.U.; NISHIJIMA, W.; OKADA, M. Coagulation mechanism of salt solution-extracted active component in moringa oleifera seeds. Water Research, Londres, v.35, n.03, p.830-834, 2001.

SANTOS, W.R.; MATOS, D.B.; OLIVEIRA, B.M.; SANTANA, T.M.; SANTANA, M.M; SILVA, G.F. Estudo do tratamento e clarificação de água com torta de sementes de Moringa oleifera Lam. Revista Brasileira de Produtos Agroindustriais, Campina Grande, v.13, n.3, p.293-297, 2011. 